Günlü, Y., \& Çakmak, S. (2021). Özel gereksinimli çocuğa sahip babaların covid-19 sürecinde sunulan online eğitimlere ilişkin görüşleri. Aksaray Üniversitesi Sosyal Bilimler Enstitüsü Dergisi, 5(2), 148-162. doi: 10.38122/ased.52.3

Makale Geçmişi / Article History

Alindl (Received): 05/08/2021

Düzeltme Alındı (Received Revised Form): 29/12/2021

Kabul edildi (Accepted): 30/12/2021

\title{
Özel Gereksinimli Çocukları Olan Babalarının Covid-19 Sürecinde Online Eğitimlere İlişkin Görüşleri
}

\author{
Yasin GÜNLÜ ${ }^{1}$ \\ Salih ÇAKMAK ${ }^{2}$
}

Öz: Tüm dünyada hızla gelişen teknoloji ile birlikte dijitalleşme, hayatımızın tüm aşamalarında etkili olmuştur. Özellikle pandemi sürecinde, eğitim ile ilgili konularda teknoloji destekli eğitimler yaygınlaşmıştır. Pandemi sürecinde diğer eğitim alanları ile birlikte özel eğitim alanında da online eğitimlerin sayısında artış olduğu bilinmektedir. Bu eğitimlerin hem özel gereksinimi olan bireylere hem de ailelerine sunulduğu görülmektedir. Özellikle ailelere pek çok platformda aile eğitimleri sunulmaktadır. Ancak bu durum tartışmaları da beraberinde getirmiştir. Özel gereksinimli çocuğu olan ailelerin online eğitimlere erişebilirliği, eriştiği online eğitimlerin kendilerinin ve çocuklarının ihtiyaçlarını ne denli karşıladığı ve etkilediği güncel ve merak uyandıran bir konu olmuştur. Bu gerekçeler ile yapılan bu çalışmada, özel gereksinimli çocuğa sahip babalarının covid-19 sürecinde online eğitimlere ilişkin görüşlerini belirlemek amaçlanmıştır. Araştırma, nitel araştırma desenlerinden fenomenolojik araştırma yöntemine uygun olarak yarı yapılandırılmış görüşme formları kullanarak, yüz yüze görüşmeler ile yürütülmüştür. Araştırmanın katılımcılarını özel gereksinimli çocuğu olan 10 baba oluşturmuştur. Araştırmada elde edilen bulgular, babaların online eğitimlere erişmede, haberdar olmada ve verilen eğitimlerin gerçek hayatta uygulanmasına yönelik eksikler olduğunu göstermekle birlikte, babaların online eğitimlere ilişkin farklı öneriler sunduğu görülmektedir.

Anahtar Kelimeler: Online özel eğitim, baba görüşleri, covid 19

\section{Opinions of Fathers With A Child with Special Needs on Online Trainings Offered During The Covid-19 Process}

\begin{abstract}
Digitalization with the rapidly developing technology all over the world has been effective in all stages of our lives. Especially during the pandemic process, technology-supported trainings on educationrelated issues have become widespread. It is known that there has been an increase in the number of online trainings in the field of special education along with other fields of education during the pandemic process. It is seen that these trainings are offered to both individuals with special needs and their families. In particular, family trainings are offered to families on many platforms. However, this situation has also brought about discussions. The accessibility of online education for families with children with special needs and the extent to which the online education they access meet and affect their own and their children's needs has been a topical and intriguing issue. For these reasons, in this study, it was aimed to determine the views of fathers of children with special needs regarding online education during the covid-19 process. The research was conducted with face-to-face interviews using semi-structured interview forms in accordance with the phenomenological research method, one of the qualitative research designs. The participants of the study consisted of 10 fathers with special needs children. Although the findings of the study show that fathers have deficiencies in accessing and being aware of online trainings and in applying the trainings in real life, it is seen that fathers offer different suggestions regarding online training.
\end{abstract}

Keywords: Online special education, father's opinions, covid 19

\section{Summary}

Through planned and structured family education programs, families with children with special needs can take an active role in their children's education. (Cavkaytar, 1999). Family education is important for families to be the people with the most interaction with their children, to know their children well, to have more interaction

\footnotetext{
${ }^{1}$ Arş. Gör., Aksaray Üniversitesi, Eğitim Fakültesi, Özel Eğt. Böl., e-posta: gunluyasin@ gmail.com, ORCID: 0000-0003-4308-2192

${ }^{2}$ Doç. Dr., Gazi Üniversitesi, Eğitim Fakültesi, Özel Eğt. Böl., e-posta: salih_cakmak@ gazi.edu.tr ORCID: 0000-0002-9248-0050
} 
time with their children than other educators, to reduce the education costs of their children, and to provide education services by educating families to children who cannot be directly served (Fox ve Binder, 1990). The pandemic process has already been added to the rapidly digitalizing education, and at the same time, with the closure of schools within the scope of the pandemic measures taken, the families have to meet their children's educational needs online. Distance education or internet-based family education applications provide significant benefits compared to traditional family education applications in terms of cost, transportation and flexible use of time. Therefore, considering the results of the studies examined, distance education can be an alternative for parents who have problems in accessing family education services. However, when online applications began to take place, some difficulties surfaced. For example, it has sometimes been a problem for students with low socio-economic status to access online education tools such as the internet and computers. This situation has become more evident and observable during the pandemic process (Varışl1, 2021). However, in order for families to access online services, they must have the necessary digital infrastructure and equipment (Kizir, 2021). In this study, it is aimed to determine the views of fathers of children with special needs regarding online education during the covid-19 process. The research was conducted as a qualitative research using the phenomenological research method. The participants of the study are 10 fathers residing in Aksaray, who have children with special needs and whose children are educated in any special education institution. The main data collection tool of phenomenological studies is interviews. The interview is to collect data from the sample about the questions to be answered in the research. Interviews provide in-depth information on a particular research topic or question (Büyüköztürk, Kılıç Çakmak, Akgün, Karadeniz ve Demirel, 2012). The most basic source of information in phenomenological research is interviews (Y1ldırım ve Şimşek, 2011). In this study, a semi-structured interview form data collection tool was used. This form consists of personal information including demographic information and questions to determine the level of relationship of participants with online family training programs. Semi-structured interview forms allow the interviewees to express themselves better and to obtain in-depth information (Büyüköztürk, Kılıç Çakmak, Akgün, Karadeniz ve Demirel, 2012). The data collection tool in this study consists of two parts. The first part contains demographic information about fathers. The second part is a form consisting of eight open-ended questions. Data were collected by the first author of the study. Before interviewing the fathers, the researcher prepared an interview schedule. While preparing the meeting schedule, all fathers were contacted and the date and time they were available were determined. The interviews were made face to face at Aksaray University. First, the author asked the questions in the personal information form to the fathers. Then, each question in the semi-structured interview form was directed to the fathers and the fathers' answers were recorded on a voice recorder. After all questions were asked, the fathers were thanked and the data collection process was completed. The inductive method was used to analyze the data and to obtain in-depth information to reveal the views of the participants. As a result of the study, it is seen that fathers have different views on online education during the covid-19 process and make different suggestions in this direction. Firstly, it was concluded that fathers participated very little in face-to-face family education programs in previous years. Only two fathers (F5, F10) stated that they participated in face-to-face training. When the literature is reviewed, it is seen that mothers participate in family education programs more than fathers (Batu, 2008; Özen \& Kurcaali-İftar, 2000; Tekin-İftar, 2008). Therefore, this finding of the study is not surprising. In fact, it is interpreted that children with special needs are mostly supported by their mothers. Another finding reached as a result of the study is that fathers participate in online trainings in different numbers. While the number of fathers participating in at least one online training is three, the number of fathers participating in more than one online training is one. It has been concluded that fathers are mostly aware of the increasing online training during the Covid-19 process through social media. In the study, it was found that fathers mostly $(n=8)$ participate in online family education programs by telephone. Fathers stated that the computer at home is used by their children for playing games and attending distance lessons, and therefore they attend the trainings over the phone. Fathers listed the positive aspects of online family training; accessible $(n=10)$, done in a short time $(n=10)$, in their own environment $(n=8)$ without having to open a camera $(n=6)$. Features of online education that fathers stated negatively; the language used in online training $(n=7)$, the difficulties experienced in internet connection $(n=6)$ and the lack of application examples $(n=4)$. It is very important for learning to include practice examples in the trainings offered on self-care, daily life and academic skills. However, as stated in most studies, the lack of sample applications in online training is seen as a limitation. The fathers who participated in the study listed their suggestions for online training as follows; improving internet connections, conducting individual trainings, including corrective feedback and repetitions in these trainings, making training announcements more widely and providing material support. 


\section{GIRIŞ}

Özel gereksinimli çocuğa sahip ailelerin, çocuklarının eğitimlerinde aktif rol oynamaları, planlı ve yapılandırılmış aile eğitim programları aracılığı ile sağlanabilmektedir (Cavkaytar, 1999). Aile eğitimi, ailelerin çocuklarını en fazla etkileşim içinde olan kişiler olmaları, çocuklarını iyi tanımaları, çocukları ile etkileşim sürelerinin diğer eğiticilerden fazla olması, çocuklarının öğretim masraflarını azaltması ve doğrudan hizmet götürülemeyen çocuklara ailelerin eğitilerek eğitim hizmetin götürülmesi konularında önemli olmaktadır (Fox ve Binder, 1990). Ayrıca sadece özel gereksinimli çocukların ailelerinin eğitilmesi değil sosyal hayatın tüm alanlarında daha maliyetsiz eğitim modelleri üzerinde çalışmalar devam etmektedir. Artan nüfus ile birlikte ülkeler, eğitim maliyetinin düşürülmesi, toplumun sürekli gelişen ve değişen dünyaya ayak uydurabilesi için yaşam boyu eğitime yönelmişler ve yaşam boyu eğitime katkı sağlayacak birçok sistem geliştirmişlerdir. Bunlardan biri de "Uzaktan Eğitim” kavramıdır (Özbay, 2015). Ülkemizde uzaktan eğitim çalışmaları "Öğretmen Eğitimi Raporu” ile 1924 yılında tartışmaya başlanmıştır. 1950 yılında ise Türk Eğitim Sisteminde ilk uzaktan eğitim uygulamaları mektup ile öğretimle başlamıştır (İşman, 2011). Uzaktan eğitim, zaman ve ortam serbestliğinin yanı sıra kullanılan uygulamalara göre farklı etkileşim düzeyleri sunarak günümüze değin gelmiştir (Akdemir, 2011).

Uzaktan eğitim uygulamalarından yararlanan gruplardan biri de ailelerdir. Uzaktan aile eğitim uygulamaları, çevrimiçi (online), çevrimdışı (offline) olarak veya her ikisinin birlikte kullanımıyla gerçekleştirilebilmektedir (Şen, Atasoy, \& Aydın, 2010). Teknolojide yaşanan gelişmeler, çevrimiçi eğitimlerin yaygınlaşmasına ve daha çok tercih edilmesine zemin hazırlamıştır.

Hâlihazırda hızla dijitalleşen eğitime, pandemi süreci de eklenmiş aynı zamanda okulların alınan pandemi tedbirleri kapsamında kapanması ile de ailelerin çocuklarına ilişkin eğitim ihtiyaçlarını çevrimiçi karşılama zorunluluğu doğmuştur. Uzaktan veya internet temelli aile eğitim uygulamaları maliyet, ulaşım ve esnek zaman kullanımı bakımından geleneksel aile eğitim uygulamalarına göre önemli yararlar sağlamaktadır. Dolayısıyla incelenen çalışmaların sonuçları göz önünde bulundurulduğunda aile eğitim hizmetlerine ulaşmada sorun yaşayan ebeveynler için uzaktan eğitim bir alternatif olabilmektedir. Ancak çevrimiçi uygulamalar gerçekleşmeye başladığında bazı güçlükler gün yüzüne çıkmıştır. Örneğin, alt sosyo-ekonomik statüden öğrencilerin internet ve bilgisayar gibi çevrimiçi eğitim araçlarına ulaşmaları kimi zaman sorun olmuştur. Bu durum pandemi sürecinde daha çok belirgin ve gözlenebilir hale gelmiştir (Varışl1, 2021). Ancak bu hizmete ulaşabilmek için gerekli altyapı ve donanıma sahip olunması gerekliliği bulunmaktadır (Kizir, 2021). Uluslararası alanyazın incelendiğinde, özel eğitim hizmetlerinin uzaktan yürütüldüğü çalışmalarda karşımıza 'telehealth' kavramı çıkmaktadır. Telehealth; sağlık, özel eğitim, psikolojik danışma gibi hizmetlerin uzaktan yapılması olarak adlandırılmaktadır. Literatürde "telemedicine" ya da 
"telepractice" olarak yerini almıştır. Bahsi geçen kavramların tümü yüz yüze görüşülmenin imkan dahilinde olmadığı durumlarda görüşmeleri online bir yöntemle yürütülme tekniğini ifade etmektedir (Boutain, Sheldon \& Sherman, 2020). Araştırmalar incelendiğinde yüz yüze eğitimin mümkün olmadığı durumlarında online düzenlenen eğitimin, yüz yüze yapılan eğitim kadar etkili olmadığı söylenebilir. Ancak sıkça tüm dünya literatüründe bahsedildiği gibi pandemi sürecinde eğitim sisteminin durmaması ve bireylerin eğitim öğretimden geri kalmamaları için neredeyse tüm eğitim alanlarında online etkinlikler planlanmaktadır.

$\mathrm{Bu}$ araştırmada, özel gereksinimli çocuğa sahip babalarının covid-19 sürecinde online eğitimlere ilişkin görüşlerini belirlemek amaçlanmıştır. Bu genel amaç doğrultusunda, çevrimiçi yürütülen özel eğitim hizmetlerinden babaların ne kadar haberdar olduklarını, bu etkinlikten ne düzeyde faydalandıklarını, katıldıkları etkinlikler hakkında yaşantılarını ve bu etkinliklere nasıl katıldıkları belirlemeye yönelik alt amaçlar dahilinde sorular oluşturulmuştur.

\section{YÖNTEM}

Araştırmanın bu bölümünde, araştırmanın modeli, katılımcıları, veri toplama araçları, verilerin analizi ve geçerlik güvenirlik başlıklarına yer verilmiştir.

\section{Araşturma Modeli}

$\mathrm{Bu}$ çalışma, nitel araştırma desenlerinden fenomenolojik araştırma yöntemine göre desenlenmiştir. Bir anlatı araştırması bir veya birkaç kişinin deneyimlerine ilişkin hikâyeleri rapor ederken, fenomenolojik çalışma birkaç kişinin bir fenomen veya kavram ile ilgili yaşanmış deneyimlerin ortak anlamını tanımlar. Fenomenolojik çalışmalar ayrıca bir fenomeni deneyimleyen bütün katılımcıların ortak özelliklerinin tanımlanmasına odaklanır (Creswell, 2011). İnsanlara tümüyle yabancı olmayan aynı zamanda tam anlamının kavranmadı̆̆ı olguları araştırmayı amaçlayan çalışmalar için fenomenolojik yöntem iyi bir araştırma ortamı oluşturmaktadır (Yıldırım ve Şimşek, 2011). Bu nedenle babaların online eğitimlere ilişkin görüşlerinin belirlenmesi amacını taşıyan bu araştırma, fenomenolojik araştırma yöntemine uygun olarak yarı yapılandırılmış görüşme formları kullanarak yürütülmüştür.

\section{Katılımclar}

Yürütülen bu araştırmada, Aksaray ilinde ikamet eden, özel gereksinimi çocuğa sahip ve çocukları herhangi bir özel eğitim kurumunda eğitim alan babalar katılımcı olarak belirlenmiştir. Katılımcıları belirlemek için özel eğitim kurumlarına randevulu ziyaretler planmış ve araştırmaya katılım sağlayacak babaların ön belirlemesi ile ilgili kurum yetkilileri ile toplantılar yapılmıştır. Toplantılar 
sonrası kurum yetkilileri tarafından bilgilendirilen babalar ile araştırma yürütücüleri bir araya gelmişler ve araştırmanın içeriği hakkında bilgi vermişlerdir. En az bir kez online eğitimlere katılmış olması ön koşulunu karşılayan ve araştırmaya gönüllü olarak katılmayı kabul eden babalar ile yarı yapılandırılmış görüşmeler gerçekleştirilmiştir. Katılımcı babalara ilişkin detaylı bilgiler tabloda yer almaktadir.

Tablo 1. Kat1lımc1lara ait özellikler

\begin{tabular}{lcc}
\hline Katılımcı & Baba & 10 \\
\hline Yaş & $20-30$ & 1 \\
\cline { 2 - 3 } & $30-40$ & 4 \\
\cline { 2 - 3 } & $40-50$ & 2 \\
\hline Eğitim durumu & $50-60$ & 3 \\
& İlköğretim & 1 \\
\cline { 2 - 3 } & Ortaöğretim & 7 \\
\cline { 2 - 3 } & Ön lisans & 1 \\
\cline { 2 - 3 } & Lisans & - \\
\cline { 2 - 3 }
\end{tabular}

Tablo 1 incelendiğinde katılımcıların tamamını babalar $(\mathrm{n}=10)$ oluşturmaktadır, katılımcıların yaşlarının 20 ila 50 üstü yaş arasında olduğu, en fazla 30-40 yaş $(n=4)$, en az ise 20-30 yaş $(n=1)$ aralığında olduğu görülmektedir. Katılımcı babaların eğitim durumları ise, ilköğretim $(n=1)$, ortaöğretim ( $\mathrm{n}=7)$, ön lisans $(\mathrm{n}=1)$, lisans $(\mathrm{n}=1)$ olduğu görülmektedir.

\section{Veri Toplama Aracı}

Fenomonolojik araştırmalarda başlıca veri toplama aracı görüşmelerdir. Görüşme, araştırmada cevabı aranan sorular ile ilgili örneklemden veri toplamak olarak ifade edilebilir. Görüşme belirli bir araştırma konusu veya bir soru hakkında derinlemesine bilgi sağlar (Büyüköztürk, Kılıç Çakmak, Akgün, Karadeniz ve Demirel, 2012). Olgu bilim araştırmalarında en temel bilgi kaynağı görüşmedir (Yıldırım ve Şimşek, 2011). Bu araştırmada demografik bilgileri içeren kişisel bilgi formu ve katılımcıların çevrimiçi aile eğitim programları ile ilişski düzeyini belirlemeye yönelik sorulardan oluşan yarı yapılandırılmış görüşme formu veri toplama aracı kullanılmıştır. Yarı yapılandırılmış görüşme formları, görüşülen bireylerin kendilerini daha iyi ifade etmesine ve derinlemesine bilgi elde edilmesinde önemli bir yere sahiptir (Büyüköztürk, Kılıç Çakmak, Akgün, Karadeniz ve Demirel, 2012). Bu araştırmada iki bölümden oluşan veri toplama aracı kullanılmıştır. İlk bölümde babalara ilişkin demografik bilgiler yer almaktadır. İkinci bölümde ise sekiz açık uçlu sorudan oluşan bir formu bulunmaktadır. Araştırmacılar tarafından geliştirilen yarı yapılandırılmış görüşme formunun oluşturulma sürecine dair bilgiler aşağıda sunulmuştur.

$\mathrm{Bu}$ araştırmada, babaların çevrimiçi eğitimler ile ilişkilerini belirlemek amacıyla yarı yapılandırılmış görüşme yöntemi kullanılmıştır. Bu amaç doğrultusunda babalara, yazarlar tarafindan geliştirilen, 8 
sorudan oluşan görüşme formu uygulanmıştır. Görüşme formunun hazırlanmasında şu basamaklar izlenmiştir; 1) İlk olarak çalışmanın amacı doğrultusunda literatür taraması yapılmıştır. 2) Literatür taramasından sonra araştırmacılar tarafından soru havuzu oluşturulmuştur. 3) Oluşturulan soru havuzu araştırmacılar tarafından tek incelenmiş ve diğer sorularla benzerlik göstermesi nedeniyle 4 soru havuzdan çıkarılmıştır. 4) Ardından 8 sorunun yer aldığı görüşme formu, özel gereksinimli çocuğu olan ve veri toplama sürecinde yer almayan 3 babaya sorulmuştur. 5) Sorulardan biri, bir baba tarafından anlaşılmadığ 1 için dil bakımından tekrar yazılmış diğer bir soru da başka bir baba tarafından başka bir soru ile aynı algılandığı için görüşme formundan çıkarılmıştır. 6) Sorular babalardan alınan dönütler ile düzenlendikten sonra yeniden 3 farklı babaya sorulmuştur, babalardan gelen yanıtlar soruların açık ve anlaşılır olduğunu ortaya koymuştur. Bu durum araştırmacıların hedeflenen veriyi elde edebilecek nitelikte sorular oluşturulduğu şseklinde yorumlanmıştır. Araştırmacılar tarafından sorular yeniden incelenmiş ve gerekli düzeltmeler yapıldıktan sonra görüşme formuna son hali verilmiştir.

Oluşturulan görüşme formları ile veriler, araştırmanın birinci yazarı tarafından toplanmıştır. Yazar, babalarla görüşme yapmak için öncelikli görüşme takvimi hazırlamıştır. Görüşme takvimini her babayı tek tek arayarak en uygun oldukları tarih ve saati belirleyerek oluşturmuştur. Belirlenen tarih ve saatte, Aksaray Üniversitesi Engelli Öğrenci Birimi’nde babalarla yüz yüze görüşmeler gerçekleştirilmiştir. Yazar, ilk olarak kişisel bilgi formunu ardından da yarı yapılandırılmış görüşme formunda yer alan her bir soruyu babaya yöneltmiş ve cevaplarını ses kayıt cihazına kaydetmiştir. Tüm soruları tamamladıktan sonra babaya teşekkür ederek veri toplama sürecini sonlandırmıştır.

\section{Verilerin Analizi}

Verilerin analizinde, katılımcıların görüşlerini ortaya koymak ve derinlemesine bilgi elde etmek amacı ile fenomenolojik bakış açısı ile tümevarım analizi gerçekleştirilmiştir (Creswell, 2002; Kuş, 2003). Creswell'e, (2011) göre fenomenolojik çalışmalar ayrıca bir fenomeni deneyimleyen bütün katılımcıların ortak özelliklerinin tanımlanmasına odaklanır. $\mathrm{Bu}$ görüşten yola çıkarak fenomenolojinin bireylerin doğrudan yaşadıkları ve deneyimlediklerini betimlemeye çalışan bir yöntem olduğu belirtilmektedir (Larkin, Wattts ve Clifton, 2006). Araştırmada ortaya çıkan görüşler bir bütün olarak ele alınmış ve olayların algılanabilen yönü anlamına gelen fenomenler incelenerek analiz edilmiştir. Böylece babaların online eğitimlere ilişkin görüşlerine ve yaşantılarına derinlemesine odaklanılması amaçlanmıştır.

Araştırmanın her iki yazarı tüm dökümleri birbirinden bağımsız okumuşlar ve yine birbirinden bağımsız olarak tema ve alt temaları oluşturmuşlardır. Araştırmacılar daha sonra bir araya gelerek, 
bağımsız oluşturdukları temaları ve alt temaları aralarında fikir birliğine varıncaya kadar karşılaştırarak düzenlemişler ve bulguları ortaya koymuşlardır. Temalar ve alt temalar ilişkin katılımcıların ifadelerine doğrudan yer verilmiştir.

\section{Geçerlik ve Güvenirlik}

Araştırmada verilerin güvenirliğini ortaya koymak amacıyla kodlayıcılar arası güvenirlik verisi toplanmıştır. Kodlayıcılar arası güvenirlik için öncelikle araştırmacılar sorulara verilen yanıtların her birini birer birer ele alarak okumuşlar ve notlar oluşturmuşlardır. Ardından benzerlikler göstermekte olan yanıtları bir başlık altında toplayarak tanımlamışlardır. Sonra verilen başlık bu grup için kod olarak kabul edilmiştir. İzleyen adım olarak araştırmacılar her soru için analizi tamamlamışlardır. Elde edilen yanıtlar kodlara göre düzenlenmiş ve kodlayıcılar arası uyuma bakılmıştır. Uyum \%98100 aralığında gerçekleşmiştir.

\section{BULGULAR}

Özel gereksinimi olan çocuğa sahip babaların Covid-19 sürecinde online eğitimlere ilişkin görüşlerini ortaya koymayı hedefleyen çalışmanın bu bölümünde, babalarla yapılan görüşmeler sonucunda ortaya çıkan bulgulara yer verilmiştir.

1. 'Daha önce özel eğitim alanı ile ilgili yüz yüze sunulan aile eğitim programına katıldınız mı?' sorusuna ilişkin bulgulara aşağıdaki tabloda yer verilmiştir.

Tablo 2. Daha önce özel eğitim alanı ile ilgili yüz yüze sunulan aile eğitim programına katıldınız mı?’ sorusuna ilişkin bulgular

\begin{tabular}{lll}
\hline Daha önce özel eğitim alanı ile ilgili yüz yüze & Evet & Hayır \\
\cline { 3 - 3 } sunulan aile eğitim programına katıldınız mı? & $2(\mathrm{~K} 5, \mathrm{~K} 10)$ & $8(\mathrm{~K} 1, \mathrm{~K} 2, \mathrm{~K} 3, \mathrm{~K} 4, \mathrm{~K} 6$, \\
& & $\mathrm{K} 7, \mathrm{~K} 8, \mathrm{~K} 9)$
\end{tabular}

Tablo 2'de görüldüğü üzere çalışmaya katılan 10 babadan yalnızca 2'si (K5, K10) yüz yüz sunulan aile eğitim programına katılmıştır. 8 babanın ise herhangi bir aile programına katılmadı̆̆ görülmektedir. Aşağıda katılımcı ifadelerine yer verilmiştir.

K5: '2017 yllında kurum sahibinin biri ardı beni Ë̆itime kurum sahibinin kendisini telefon ile arayarak davet etti yani... önce gitmek istemedim tabi alışkın olduğum gibi değil yani ben ortaokuldan sonra kendi mesleğimde çalıştım defter kitap ek işim olmadl, ama büyük kızım ısrar edince gittim.'

K2: 'Hocam benim mesleğim gereği ev geç gidiyorum zaten çocuklarl gördüğ̈̈m toplasan yatmadan iki saat, ara sıra rehabilitasyondan ararlar ama servis işi ne bileyim rapor alınması gibi onu da ben götürür hallederim başka ĕgitim vs yok hocam gitmedim işin doğrusu...' 
K10: '30 saatlik bir sertifika programı düzenlendi, milli eğitim yapmış̧ı onu aldık ama işimize yarar diye ... yöneticilik yaptı̆̆ım için kendi işim ile ilgili sertifika programına katıldım.'

K8: 'Aslında birkaç kez eşim söyledi, ama o katıldı ben gidemedim malum iş güç.'

K1: 'Valla değerli hocam çocuk benim çocuğum ama genelde annesi ilgileniyor şimdi düşünüyorum ben gitmeye gitmedim.'

2. 'Çocuğunuzun özel gereksinimi ya da özel ĕgitim alanı ile ilgili, çevrimiçi (online) ders, kurs yada herhangi bir eğitime katıldınız mı? Katıldı iseniz kaç kez katıldınız?' sorusuna ilişkin bulgular aşağıdaki tabloda yer verilmiştir.

Tablo 3. 'Çocuğunuzun özel gereksinimi ya da özel eğitim alanı ile ilgili, çevrimiçi (online) ders, kurs yada herhangi bir eğitime kaç kez katıldınız?’ sorusuna ilişkin bulgular

\begin{tabular}{lllllll}
\hline Çevrimiçi (online) ders, & $1 \mathrm{kez}$ & $2 \mathrm{kez}$ & $3 \mathrm{kez}$ & $4 \mathrm{kez}$ & $5 \mathrm{kez}$ \\
\cline { 4 - 6 } kurs yada herhangi bir & $3(\mathrm{~K} 1, \mathrm{~K} 2, \mathrm{~K} 3)$ & $2(\mathrm{~K} 4, \mathrm{~K} 7)$ & $3(\mathrm{~K} 6, \mathrm{~K} 8, \mathrm{~K} 9)$ & $1(\mathrm{~K} 10)$ & $1(\mathrm{~K} 5)$ \\
eğitime kaç kez katıldınız? & & & & &
\end{tabular}

Tablo 3 incelendiğinde, katılımcıların tamamının en az bir kez online düzenlenen programlara katılım sağladığı görülmektedir. Üç katılımcının (K1, K2, K3) 1 kez, yine 3 katılımcının (K6, K8, K9) 3 kez, iki katılımcının (K4, K7) iki kez, bir katılımcının (K10) 4 kez ve bir katılımcının (K5) 5 kez online programa katıldığı görülmektedir. Aşağıda katılımcı ifadelerine yer verilmiştir.

K6: 'Hocam pandemi döneminde malum iş yerlerimiz kapandı. Bu süreçte sosyal medyada ne gördük ise katılmaya çalıştım. Eşimle takip ettik.'

K1: 'Hocam biz ögretmenden Allah razı olsun bir kere topladı bizi uzun uzun evde nasıl davranalım anlattr.'

K10: 'Ben sosyal medyada zaten çoğu hocalarl takip ediyorum, sizi de tabi hocam. Oradan eşimle baklyorduk, bir de ücretsiz ne gördük ise dahil olduk.'

3. 'Online sunulan eğitimlere hangi yollarla ulaştınız?' Sorusuna ilişkin bulgular ve yorumlarına aşağıdaki tabloda yer verilmiştir. 
Tablo 4. 'Online sunulan eğitimlere hangi yollarla ulaştınız?' Sorusuna ilişkin bulgular

\begin{tabular}{ll}
\hline Online sunulan eğitimlere hangi yollarla ulaştınız? & $N$ \\
\hline Sosyal medya & $7(\mathrm{~K} 2, \mathrm{~K} 3, \mathrm{~K} 4, \mathrm{~K} 5, \mathrm{~K} 6, \mathrm{~K} 9, \mathrm{~K} 10)$ \\
\hline Öğretmen & $1(\mathrm{~K} 1)$ \\
\hline Diğer (arkadaş, akraba vb.) & $2(\mathrm{~K} 7, \mathrm{~K} 8)$
\end{tabular}

Tablo 4 incelendiğinde katılımcıların büyük bir çoğunluğunun $(n=7)$ online sunulan programlardan sosyal medya aracılığı ile haberdar olduğu görülmektedir. En az ise öğretmenler aracıllı̆̆ ile haberdar olan katılımcının ( $\mathrm{n}=1)$ olduğu görülürken, 2 katılımcının arkadaş ya da akraba aracılığı ile bu tür programlardan haberdar oldukları görülmektedir. Aşağıda katılımcı ifadelerine yer verilmiştir.

K6: 'Hocam bu hastalıkta biz telefonla daha çok uğraştık. Benim facebook, instgram falan yoktu .... Onlar sayesinde bir sürü hoca takip ediyoruz, onlardan duyuyoruz. Ücretsiz olanların hepsi de katıldık.'

K1: 'Hocam bizim hocamız özel ĕgitimci ara ara telefonla anlattı yapılacakları ama bir kere de kendi hocasıymış o eğitim veriyormuş onu söyledi biz de katıldık bizim hanımla.'

K7: 'Hocam bizim hanım okuldan veli grubuna kayıtlıymış WhatSapp ögretmen oraya babaları da ekledi. O gruptan arkadaşlar edindik, onlar söyledi birkaç kez.'

4. 'Bu eğitimlere nasıl katılım sağladınız?' Sorusuna ilişkin bulgular ve yorumlarına aşağıdaki tabloda yer verilmiştir.

Tablo 5. ‘Bu eğitimlere nasıl katılım sağladınız?’ Sorusuna ilişkin bulgular

\begin{tabular}{ll}
\hline Bu ĕ̈itimlere nasll katılım să̆ladınız? & $N$ \\
\hline Telefon & $8(\mathrm{~K} 1, \mathrm{~K} 2, \mathrm{~K} 3, \mathrm{~K} 4, \mathrm{~K} 6, \mathrm{~K} 7, \mathrm{~K} 8, \mathrm{~K} 9)$ \\
\hline Bilgisayar/Tablet & $2(\mathrm{~K} 5, \mathrm{~K} 10)$
\end{tabular}

Tablo 5 incelendiğinde babaların büyük çoğunluğunun $(n=8)$ sunulan eğitimlere telefonla katılım sağladığı görülürken, diğer iki babanın eğitimlere bilgisayar/tablet aracılığı ile katılım sağladığ1 görülmektedir. Aşağıda katılımcı ifadelerine yer verilmiştir.

K2: 'Hocam ben telefonla katıldım en hızlı yöntem ...'

K5: 'Genelde çocuklar uyuduktan sonra oldu bu eğitimler, o zamanlar bilgisayar boş duruyordu ben de oradan giriyordum.'

5. 'Online eğitim çalışmalarına katılırken internet erişiminizi nereden (TT net, telefon internet paketi vb.) sağladınız?' Sorusuna ilişkin bulgular ve yorumlarına aşağıdaki tabloda yer verilmiştir. 
Tablo 6. 'Online eğitim çalışmalarına katılırken internet erişiminizi nereden (TT net, telefon internet paketi vb.) sağladınız?' sorusuna ilişkin bulgular

\begin{tabular}{ll}
\hline Bu eğitimlere nasıl katılım sağladınız? & $N$ \\
\hline Telefon internet paketi & $2(\mathrm{~K} 1, \mathrm{~K} 9)$ \\
\hline TT net, ev interneti vb. & $8(\mathrm{~K} 2, \mathrm{~K} 3, \mathrm{~K} 4, \mathrm{~K} 5, \mathrm{~K} 6, \mathrm{~K} 7, \mathrm{~K} 8, \mathrm{~K} 10)$ \\
\hline
\end{tabular}

Tablo 6 incelendiğinde katılımcıların büyük çoğunluğunun $(n=8)$ online eğitim çalışmalarına TT net, ev interneti vb. ile internet erişimi sağladıkları görülürken, iki katılımcının telefon internet paketi üzerinde erişim sağladıkları görülmektedir. Aşağıda katılımcı ifadelerine yer verilmiştir.

K10: 'Hocam bu süreçte biz zaten eve internet yetiştiremedik, 3 çocuk düşünün evde okul yok park yok sürekli internet ... ben de kotay yükselttim hep beraber kullandı.'

K1: 'Hocam ben ve eşimin telefonunda sinırsı internet oradan girdim.'

K8: 'En çok evde interneti ben kullanmışımdır, herhalde ... alışveriş her şey oradandı. ... Tabi ev internetinden bahsediyorum oradan giriyorum.'

6. 'Online bağlanma esnasında kullandığınız uygulamayı açma, kurma ya da kullanma ile ilgili herhangi bir yardıma ihtiyacınız oldu mu?' Sorusuna ilişkin bulgular ve yorumlarına aşağıdaki tabloda yer verilmiştir.

Tablo 7. 'Online bağlanma esnasında kullandığınız uygulamayı açma, kurma ya da kullanma ile ilgili herhangi bir yardıma ihtiyacınız oldu mu?' sorusuna ilişkin bulgular

\begin{tabular}{ll}
\hline $\begin{array}{l}\text { Online bă̆lanma esnasında kullandı̆̆ınız uygulamayı açma, } \\
\text { kurma ya da kullanma ile ilgili herhangi bir yardıma ihtiyacınız } \\
\text { oldu mu? }\end{array}$ \\
\hline Evet & $5(\mathrm{~K} 1, \mathrm{~K} 5, \mathrm{~K} 8, \mathrm{~K} 9, \mathrm{~K} 10)$ \\
\hline Hayır & $5(\mathrm{~K} 2, \mathrm{~K} 3, \mathrm{~K} 4, \mathrm{~K} 6, \mathrm{~K} 7)$
\end{tabular}

Tablo 7 incelendiğinde katılımcıların yarısı $(n=5)$ online bağlanma esnasında yardıma ihtiyaç duyduğunu belirtirken, diğer yarısı $(n=5)$ yardıma ihtiyaç duymadıklarını belirtmişlerdir. Aşağıda katılımcı ifadelerine yer verilmiştir.

K1: 'Hocam ben bir kez katıldım, orada Zoom siye bir program varmış onu anlamak da zor. Arkadaşlara sora sora yaptık.'

K10: 'Hocam programın hepsi başka bir şey kullandı. Instgramdan canlı yayın dışında hepsi yorucu oldu ama Zoom u anlamak zor, çocuklar benden daha iyi onlar hallettiler.' 
K2: 'Hocam linki bulunca sorun olmuyordu, karşımıza çıkan sayfa bizi yönlendiriyordu.'

7. 'Katıldığınız online eğitim/eğitimlerin olumlu ve olumsuz yanlarını değerlendirir misiniz?' sorusuna ilişkin bulgular ve yorumlarına aşağıdaki grafikte yer verilmiştir.

Grafik 1. Katıldığınız online eğitim/eğitimlerin olumlu ve olumsuz yanlarını değerlendirir misiniz? Sorusuna ilişkin bulgular

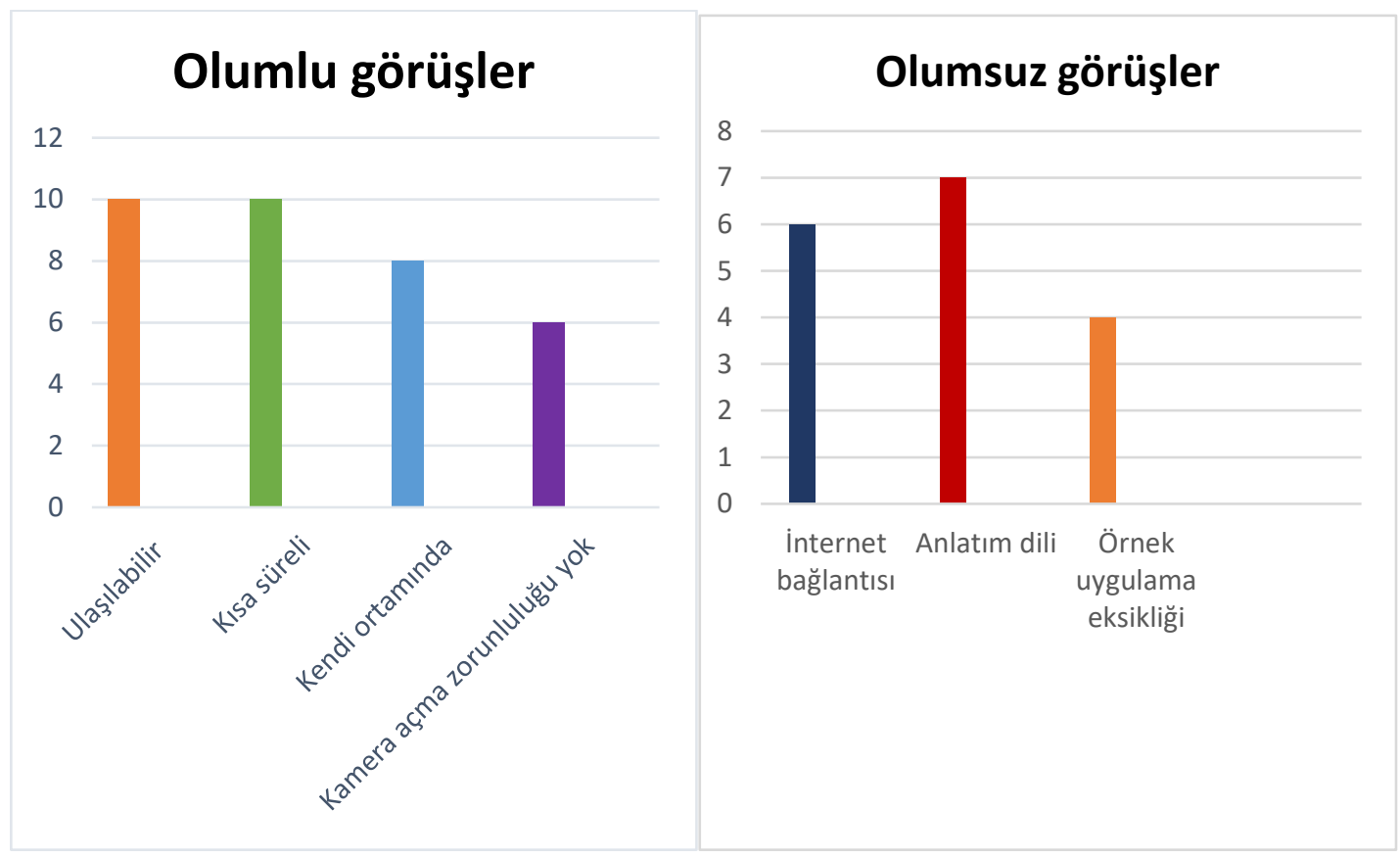

Grafik 1'de katılımcıların online eğitimleri olumlu ve olumsuz taraflarına ilişkin görüşleri yer almaktadır. Grafik de görüldüğü gibi katılımcıların tamamı $(n=10)$ online eğitimlerin ulaşılabilir olmasını ve kısa sürede gerçekleştirilmesini olumlu olarak görmüşlerdir. Bununla birlikte katılımcıların büyük çoğunluğu $(n=8)$ eğitimlere kendi ortamlarında katılmayı olumlu olarak ifade ederken, yine katılımcıların yarısından fazlası $(n=6)$ eğitimlerde kamera açma zorunluluğunun olmasını olumlu olarak görmüşlerdir.

Grafik 1 incelendiğinde katılımcıların büyük çoğunluğu $(n=7)$ eğitimler sırasında kullanılan dili ağır olarak görmüş ve olumsuz olarak değerlendirmişlerdir. Yine altı katılımcının internet bağlantısından dolayı olumsuz görüş bildirdiği görülürken altı katılımcı örnek uygulama eksikliğini de olumsuz olarak değerlendirmişlerdir. Aşağıda bazı katılımcı ifadelerine yer verilmiştir.

K2: 'Bu ĕgitimlere herkes katılabildi, telefonla tıkla gir. Bence en önemli özelliği bu ... Ama işte internet bağlantısı sorun olabilir ... Hocalar da bazen asperger diyor mesela biz onu bilsek ...' 
K10: 'En büyük avantajı herkes için ulaşılabilir olması bence. Yine evde çayını içerken girip dinliyorsun bu da önemli ... Olumsuz olarak da internet bağlantısı söylenebilir, bazen de hocalar anlatıp çıkıyor, ama uygulamayı göstermiyor, yüz yüze bu anlamda daha başarılı.'

K5: 'Olumlu olarak, evden girebilmek, ondan sonra ayağını uzat izle, gören de yok ben gezinerek dinlemeyi severim, ... içiyorum mesela böyle iyi ... Olumsuz olarak da internet mesela, bu olabilir başka aklıma gelmedi.'

8. 'Online eğitimlere ilişkin önerileriniz nelerdir?' Sorusuna ilişkin bulgular ve yorumlarına aşağıdaki grafikte yer verilmiştir.

Grafik 2. 'Online eğitimlere ilişkin önerileriniz nelerdir?' Sorusuna ilişkin bulgular

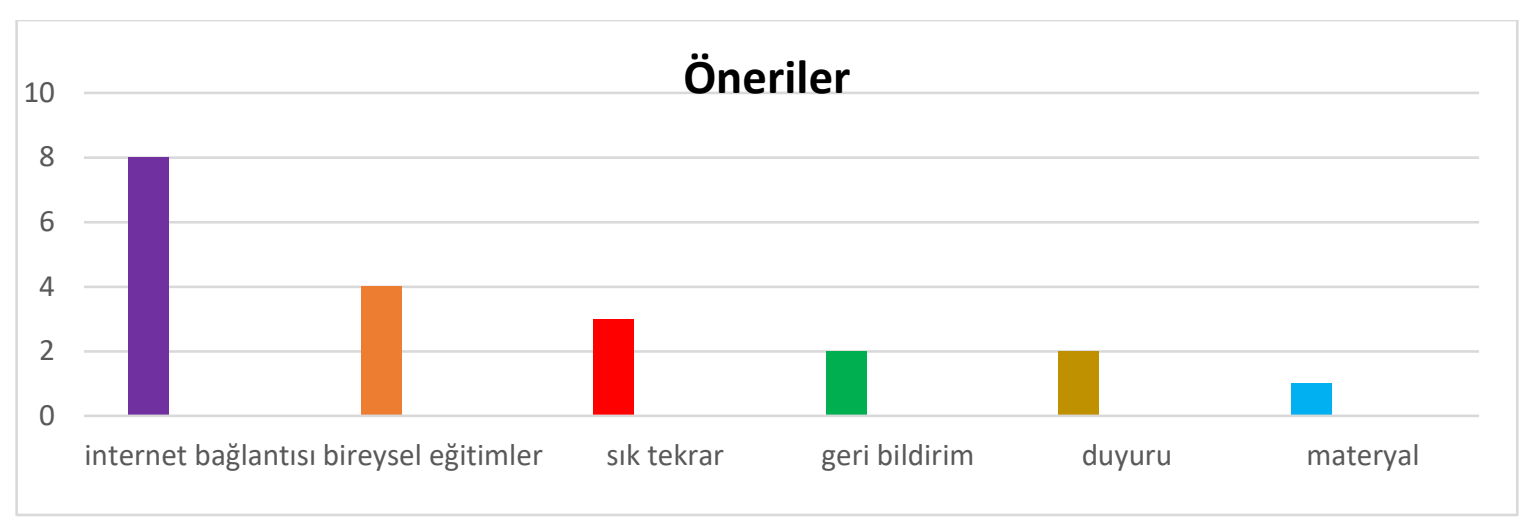

Grafik 2 incelendiğinde katılımcıların büyük çoğunluğu $(n=8)$ internet bağlantısı konusunda öneri de bulunmuşlardır. Bunu sırasıyla, bireysel eğitimler $(n=4)$, sık tekrar $(n=3)$, geri bildirim $(n=2)$, duyuru $(n=2)$ ve materyal $(n=1)$ konusunda önerilerde bulunmuşlardır. Aşağıda bazı katılımcıların ifadelerine yer verilmiştir.

K3: 'Hocam eğitimden sonra tekrar ne yaptık ne ettik bakılması lazım, bazen de diyor ki şu aracı al şu materyal bunları da bize eğitimler öncesi sunulsa çok iyi olur diye düşünüyorum.'

K2: 'Hocam bir kere değil birkaç kez aynı konu ele alınmalı. Mesela davranış bir kere anlatıldı bitti mi? Bitmedi işte tekrar tekrar anlatılmalı, bize olmuş olmamış diye bilgi verilmeli yani bunlar önemli.'

K10: 'Duyurulara daha yaygın yer verilebilir, internet bağlantısı sağlanabilir ... bir sürü şey olabilir.' 


\section{TARTIŞMA ve SONUÇ}

Yapılan çalışma sonucunda, covid-19 sürecinde babaların, online eğitimlere ilişkin farklı görüşlere sahip olduğu ve bu doğrultuda farklı önerilerde bulunduğu görülmektedir. İlk olarak, babaların geçmişte yüz yüze sunulan aile eğitimlerine oldukça sınırlı şekilde katıldığı görülmektedir. Nitekim yalnızca iki baba (K5, K10) yüz yüze eğitimlere katıldıklarını ifade etmişlerdir. Alanyazında yapılan çalışmalarda (örn., Batu, 2008; Özen \& Kırcaali-İftar, 2000; Tekin-İftar, 2008) daha çok annelerin ön plana çıktığı, babaların ise çok sınırlı şekilde aile eğitim programlarına katıldıkları bilinmektedir. Bu nedenle çalışmanın bu bulgusu, şaşırtıcı olmamakla birlikte, özel gereksinimi olan çocuklarla daha çok anneler tarafından destekler sunulduğu şeklinde yorumlanabilir.

Çalışmadan elde edilen diğer bulgu, babaların online eğitimlere farklı sayılarda katıldıklarıdır. En az bir online eğitime katılan baba sayısı üç iken, en çok katılan baba sayısı birdir. Covid-19 sürecinde artan online eğitimlerden en çok sosyal medya aracılığı ile haberdar oldukları görülmektedir. Sosyal medya kullanımının son on yılda ciddi artış göstermesi ve yine sosyal medyada eğitim duyurularının sıklıkla yapılması (Gökaliler \& Özer, 2019; Özdinç, 2014) babaların eğitimlerden haberdar olmalarını sağlamıştır. Yapılan bir çalışma ise bu araştırmanın bulguları destekler nitelikle sonuçlar ortaya koymuştur. Gökaliler ve Özer (2019) yaptıkları çalışma sonucunda, babaların sosyal medya içeriklerinde genellikle çocuk bakımı gibi konularında olduğunu ortaya koymuşlardır.

Çalışmada, babaların online gerçekleştirilen aile eğitim programlarına daha çok $(n=8)$ telefonla katılım sağladığı görülmüştür. Bunun nedeni olarak çoğu baba, evde bulunan bilgisayarın çocukları tarafından oyun oynama ve uzaktan derslere katılma amacıyla kullanıldığını ve bu nedenle telefonla eğitimlere katıldıklarını ifade etmişlerdir. Milli Eğitim Bakanlığı'nın covid-19 sürecinde dersleri uzaktan yapması, çocukların bilgisayarla daha çok vakit geçirmelerine neden olmuştur. Dolayıyla babaların eğitimlere katılımda telefon kullanması olağan bir sonuç olarak yorumlanabilir.

Çalışmada babaların büyük çoğunluğunun ( $\mathrm{n}=8)$ online eğitimlere ev interneti aracılığı ile bağlandığ görülürken, çalışmaya katılan babaların yarısının $(n=5)$ eğitimlere bağlanmak için verile programlara erişimde desteğe ihtiyaç duydukları görülmüştür. $\mathrm{Bu}$ durum babaların dijital okuryazarlık eğitimlerine ihtiyaç duydukları (Serin \& Aydın, 2021) şeklinde yorumlanabilir.

Babalar; online sunulan aile eğitimlerinin olumlu taraflarını; ulaşılabilir $(n=10)$, kısa sürede gerçekleştirilmesi $(n=10)$, kendi ortamlarında $(n=8)$ kamera açma zorunluluğu olmadan yapılması $(n=6)$ şeklinde sıralamışlardır. Nitekim alan yazında online eğitimlerin; zaman ve mekândan bağımsız öğrenme fırsatı verme, öğrenenler arasındaki fırsat eşitsizliğini giderebilme ve öğrenene bireysel sorumluluk kazandırma fırsatı sağlaması uzaktan eğitimin en önemli avantajları olarak görülmektedir 
(Yunus, Yıldırım \& Kalaycı, 2021). Dolayısıyla bu bulgu, alan yazında yapılan pek çok çalışmayı destekler niteliktedir.

Babalar, online eğitimlerde kullanılan dili $(n=7)$, internet bağlantısında yaşanan güçlükleri $(n=6)$ ve uygulama örneklerinin $(n=4)$ olmamasını olumsuz özellikler şeklinde ifade etmişlerdir. Özellikle özbakım, günlük yaşam ve elbette akademik becerilere ilişkin sunulan eğitimlerde uygulama örneklerine yer verilmesi öğrenme için oldukça önemli uygulamalar arasında yer almaktadır. Ancak pek çok çalışmada belirtildiği üzere online eğitimlerde örnek uygulamaların yapılmaması bir sınırlılık olarak görülmektedir. Bununla birlikte çalışmaya katılan babaların; internet bağlantılarının iyileştirilmesini, bireysel eğitimlere, sık tekrarlara, düzeltici dönütlere yer verilmesini, duyuruların daha yaygın yapılmasını ve materyal desteğinin sunulmasını online eğitimlere öneriler olarak sundukları görülmektedir.

\section{KAYNAKÇA}

Akdemir, Ö. (2011). Yükseköğretimimizde uzaktan eğitim. Yükseköğretim ve Bilim Dergisi, 1(2), 69-71.

Büyüköztürk, Ş., Kılıç-Çakmak, E., Akgün, Ö. E., Karadeniz, Ş., \& Demirel, F. (2012). Bilimsel araştırma yöntemleri (Geliştirilmiş 11. baskı). Ankara: Pegem Akademi.

Cavkaytar, A. (1999). Zihin engellilere özbakım ve ev içi becerilerinin öğretiminde bir aile eğitimi programının etkililiği.

Creswell, J. W. (2002). Educational research: Planning, conducting, and evaluating quantitative New Jersey: Upper Saddle River.

Creswell, J. W. (2011). Controversies in mixed methods research. The Sage handbook of qualitative research, 4, 269-284.

Fagan, J.,\& Palm, G. (2004). Fathers and early childhood programs. Cengage Learning.

Fox, R. A.,\&Binder, M. C. (1990). Parenting: a developmental-behavioral approach. Advances in Special Education.

İşman, A. (2011). Uzaktan Eğitim. Ankara: Pegem A Yayıncılık.

Özbay, Ö. (2015). Dünyada ve Türkiye'de Uzaktan Eğitimin Güncel Durumu. Uluslararası Eğitim Bilimleri Dergisi, (5), 376-394.

Kizir, M. (2021). Otizm Spektrum Bozukluğu Olan Bireylere İletişim Becerilerinin Öğretiminde Uzaktan Aile Eğitim Uygulamaları. Ankara Üniversitesi Eğitim Bilimleri Fakültesi Özel Ĕ̈itim Dergisi, 1-29.

Kuş, E. (2003). Nitel-nicel araştırma teknikleri: Sosyal bilimlerde araştırma teknikleri. Anı Yayıncılik: Ankara.

Larkin, M.,Watts, S., \&Clifton, E. (2006). Giving voice and making sense in interpretative phenomenological analysis. Qualitative research in psychology,3(2), 102-120.

Şen, B., Atasoy, F., \& Aydın, N. (2010). Düşük maliyetli web tabanlı uzaktan eğitim sistemi uygulaması. Akademik Bilişim, 10-12.

Şimşek, H.,\& Yıldırım, A. (2011). Sosyal bilimlerde nitel araştırma yöntemleri. Ankara: Seçkin Yayincilik.

Boutain, A. R., Sheldon, J. B., \& Sherman, J. A. (2020). Evaluation of a telehealth parent training program in teaching self-care skills to children with autism. Journal of Applied Behavior Analysis, 53(3). 
Tavil, Y. Z.,\& Karasu, N. (2013). Aile eğitim çalışmaları: Bir gözden geçirme ve meta-analiz örneği. Ĕgitim ve Bilim, 38(168).

Varışl1, B. (2021). Pandemi Sürecinde Eğitimin Dönüşümü: Çevrimiçi Eğitimin Sosyolojik Yansımaları. Avrasya Uluslararası Araştırmalar Dergisi, 9(26), 237-249.

Yücel, G. (2006). Bă̆ımsız otistik çocuklar eğitim merkezi hakkında uzaktan ĕgitime dayalı aile eğitim programının etkililiği (Master's thesis, Anadolu Üniversitesi).

Batu, S. (2008). Gelişimsel Yetersizliği Olan Öğrencilere Bakımlarını Yapan Kişiler Aracılığıyla Eşzamanlı İpucu Kullanılarak Ev Becerilerinin Öğretimi Education and Training in Developmental Disabilities, 43(4), 541-555.

Gökaliler, E., \& Özer, A. (2019). Baba 2.0: Dijital Dönüşüm ile Değişen Baba Rolü Üzerine Bir Araştırma. Journal of Communication Theory \& Research/Iletisim Kuram ve Arastirma Dergisi, (48).

Özdinç, T. (2014). Okul öncesi eğitimde aile katılımında sosyal medya kullanımı: Bir durum çalışması (Master's thesis, Eğitim Bilimleri Enstitüsü).

Özen, A. \& Kırcaali-İftar, G. (2000). Ailelere Uzmanlarla Çalışırken Sahip Olmaları Gereken Etkili İletişim Becerilerinin Öğretimi. Özel Eğitim Dergisi, 2(4), 59-72.

Serin, G., \& Aydın, F. (2021). Anne ve Babaların Dijital Ebeveynlik Becerileriyle İlgili Görüşlerinin Karşılaştırılması. EJERCongress 2021, 68.

Tekin-İftar, E. (2008). Parent Delivered Community-Based Instruction with Simultaneous Prompting for Teaching Community Skills to Children with Developmental Disabilities. Education and Training in Developmental Disabilities, 43(2), 249-265.

Yunus, Ö., Yıldırım, Z., \& Kalaycı, S. Uzaktan Eğitim Sürecinin Değerlendirilmesi: Fen Bilimleri Öğretmenlerinin Görüşleri. Academia Eğitim Araştırmaları Dergisi, 6(2), 477-494. 